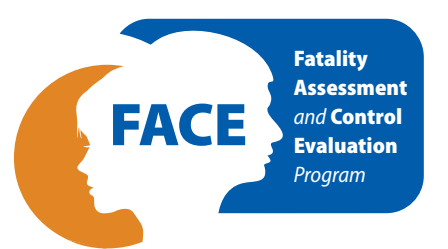

\title{
Prevent Construction Falls from Roofs, Ladders, and Scaffolds
}

Falls are the leading cause of construction worker deaths on the job.' This fact sheet gives recommendations, reports, and resources to help employers, safety professionals, and workers prevent fall injuries and deaths from roofs, ladders, and scaffolds.

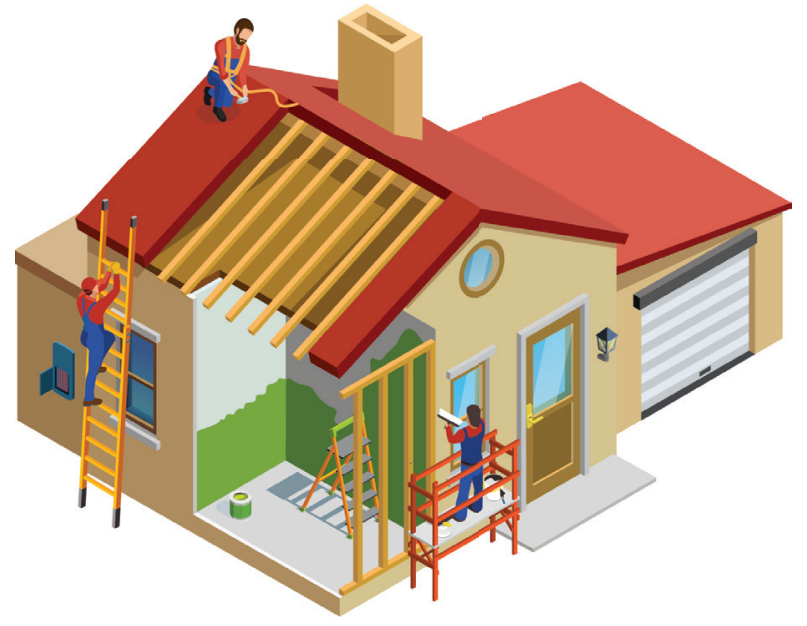

Roofs

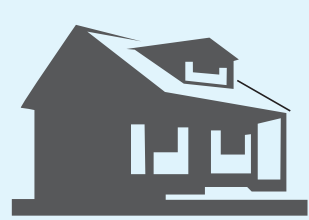

124 deaths in $2016^{2}$

$\frac{\frac{\text { Recommendations }}{\text { FACE Reports }}}{\text { Resources }}$

Ladders

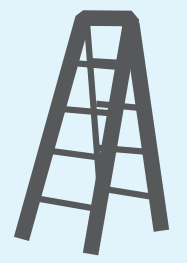

104 deaths in $2016^{2}$
Recommendations
FACE Reports
Resources

ves recommendations,
ent fall injuries and
more than
kers are killed
are seriously
heights. ${ }^{12}$
Scaffolds
dimmy
0 deaths in $2016^{2}$

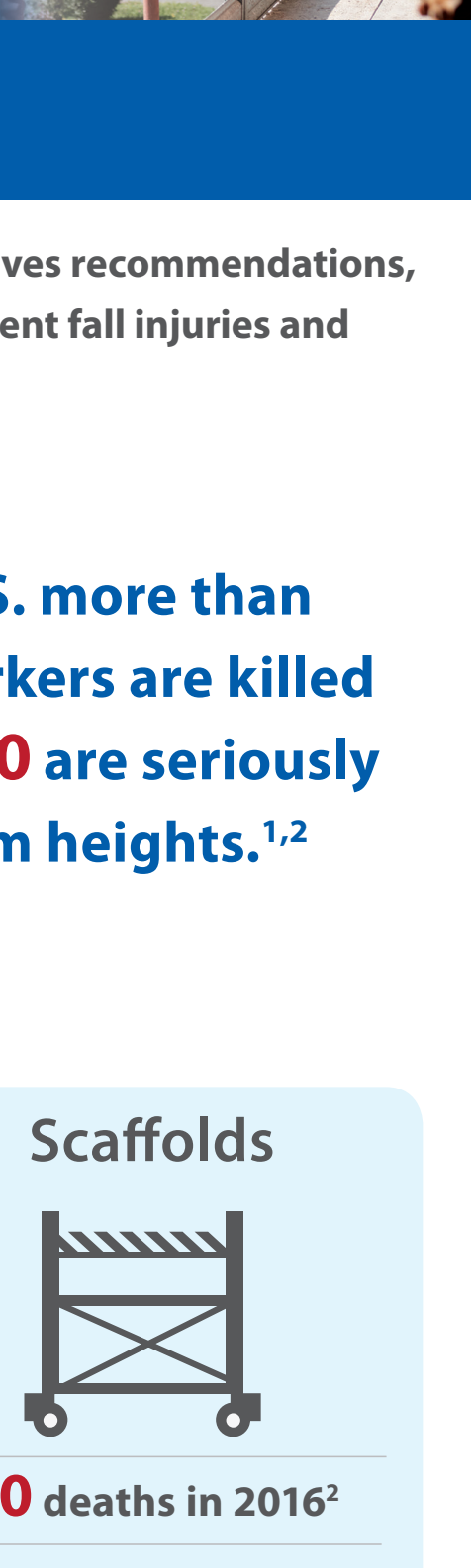

gives recommendations,
event fall injuries and
S. more than
orkers are killed
50 are seriously
om heights. ${ }^{12}$
Scaffolds
60 deaths in $2016^{2}$

Recommendations

FACE Reports

Resources

${ }^{1}$ US Department of Labor, Bureau of Labor Statistics Occupational Injuries/IInesses and Fatal Injuries Profiles-Case and Demographic Numbers. Date accessed: November 14, 2018. https://data.bls.gov/gat//nitialPage

${ }^{2}$ US Department of Labor, Bureau of Labor Statistics Occupational Injuries/lllnesses and Fatal Injuries Profiles-Fatal Injuries Numbers. Date accessed: April 6, 2018. https://data.bls.gov/gat//nitialPage 


\section{Roof Falls in Construction}

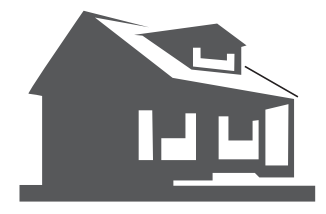

\section{$81 \%$ of deaths from roofs occur in the construction industry ${ }^{2}$}

\section{Some factors that contribute to falls from roofs:}

- Worker inexperience or lack of training

- No fall protection program or a personal fall arrest system

- No personal fall protection used

- Incorrect fall arrest system anchorage method

- Lack of fall arrest system lanyard connection point

- Incorrect working length of fall arrest system lifeline

- Working alone when working at elevations

- Working during inclement weather (e.g., wind, rain)

\section{Some recommendations to prevent falls from roofs:}

Implement a fall protection program

Wear fall protection, and use correctly

Get training on fall protection

Train and assign a person to inspect fall protection equipment before each use

$\square$ Use correct anchorage for fall arrest systems

Extend the side rails of the ladder 3 feet above the roof edge

Use a buddy system when working at heights

Monitor weather conditions

\section{Read some of our FACE reports on roof falls:}

Roofer Dies After Gust Of Wind Knocks Him and Co-Worker Off Roof - Kentucky (Report \#13KY059) A roofer and a co-worker arrived at the construction site to put a roof on a building. The roofer and co-worker climbed an extension ladder to get on top of the roof to determine where they were going to place their anchors to tie off. While reviewing the structure, a gust of wind caused both workers to fall off the roof, and one roofer died.

Hispanic Worker Falls From Residential Roof - North Carolina (Report NIOSH FACE \#2012-02)

A laborer fell from a residential roof to a concrete driveway and died from his injuries. The laborer was replacing shingles on a roof. While working on the roof, he was wearing his fall protection incorrectly. 


\section{Ladder Falls in Construction}

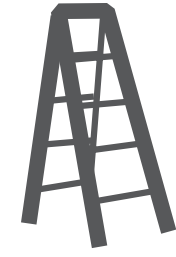

\section{$57 \%$ of deaths from ladders occur in the construction industry ${ }^{2}$}

\section{Some factors that contribute to ladder falls:}

- Worker inexperience or lack of training

- Improper ladder selection

- Improper use of a ladder

- Ladder overloading

- Ladder not set up on a flat, level surface or at a proper angle

- Not extending the ladder above the roof line

- Lack of safe access

\section{Read some of our}

\section{FACE reports on ladder falls:}

Carpenter Injured After Falling From An Extension Ladder (Report \#15MA037)

A carpenter was killed after falling from an extension ladder. The carpenter and a co-worker were onsite to do gutter work on a house. The carpenter was climbing an extension ladder that was set up on stone pavers to access the roof. While climbing the ladder, he fell when the ladder slipped out from under him. The carpenter died 16 days later.

Hispanic Worker Dies After Fall From Step Ladder While Cleaning Windows - North Carolina (Report NIOSH FACE \#2009-01)

A worker died after a fall from an 8-foot step ladder. A bucket partially filled with a cleaning solution was tied with a rag to the top of the ladder. The worker was on a ladder cleaning windows. While cleaning, he did not maintain 3 points of contact with the ladder and he fell and hit his head. 


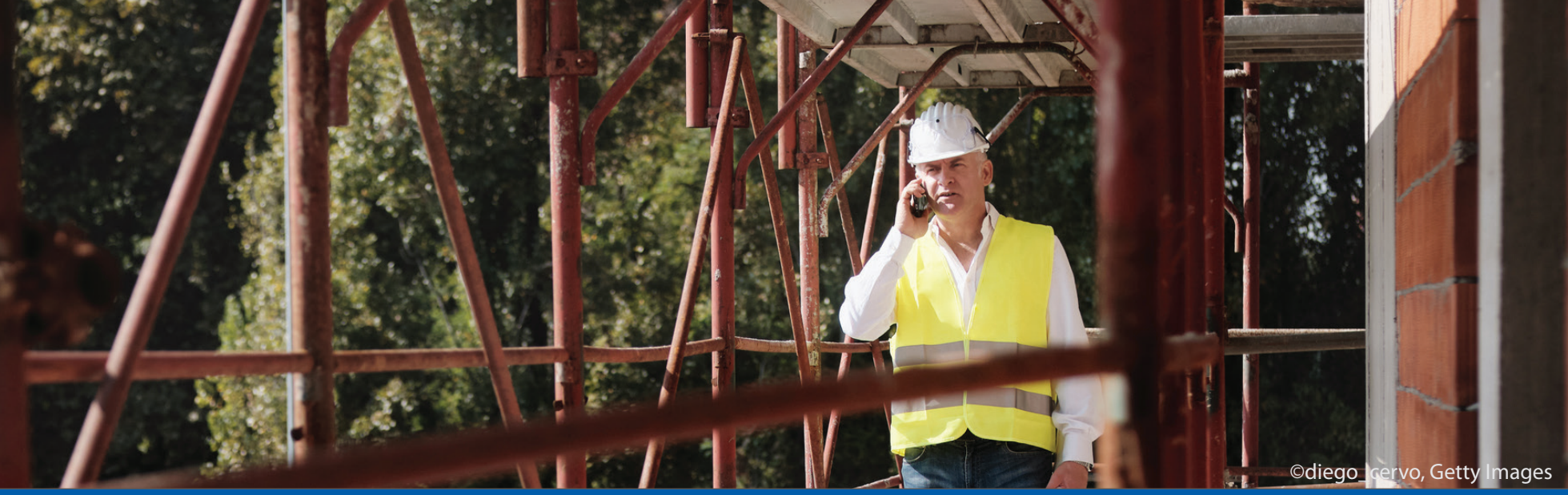

\section{Scaffold Falls in Construction}

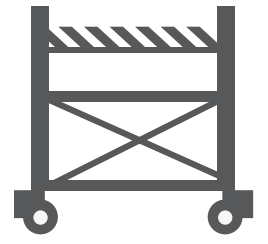

\section{$86 \%$ of deaths from scaffolds occur in the construction industry ${ }^{2}$}

\section{Some factors that}

\section{contribute to scaffold falls:}

- No fall protection program

- Worker inexperience or lack of training

- Workers not trained to identify, understand, and control fall hazards

- Lack of fall protection or fall arrest system

- Unstable work surface

- Improper scaffold construction, selection, or use

- No use of guardrails

- Wheels are unlocked before mounting the work platform

- Working alone from heights during off hours

\section{Some recommendations to prevent scaffold falls:}

Train and assign a person to supervise scaffold setup

\section{Place on stable ground/surface}

Set up scaffolds per the manufacturer guidelines and Occupational Safety and Health Administration standards

Use guardrails or a fall arrest system when more than 10 feet above a lower level

$\square$ Inspect scaffolds and scaffold parts before each use

\section{Ensure scaffolds are fully planked}

Secure scaffold (e.g., lock wheels on mobile scaffolds)

Provide proper scaffold access

\section{Read some of our}

\section{FACE reports on scaffold falls:}

Municipal Lead Custodian Dies In Fall From Mobile Scaffolding (Report \#11MA008)

A municipal custodian died while painting the inside of a school lobby. The custodian went to the school alone to finish painting. The custodian was on a mobile scaffold that was improperly set up, and he fell onto the lobby floor.

Construction Worker Died After Falling 20-25 Feet From a Pump-jack Scaffold (Report \#15OR12)

An owner of a residential siding company sustained injuries when he fell from a pump-jack scaffold platform onto a concrete slab. While working on the scaffold, the owner was not wearing fall protection. The owner died the following day. 

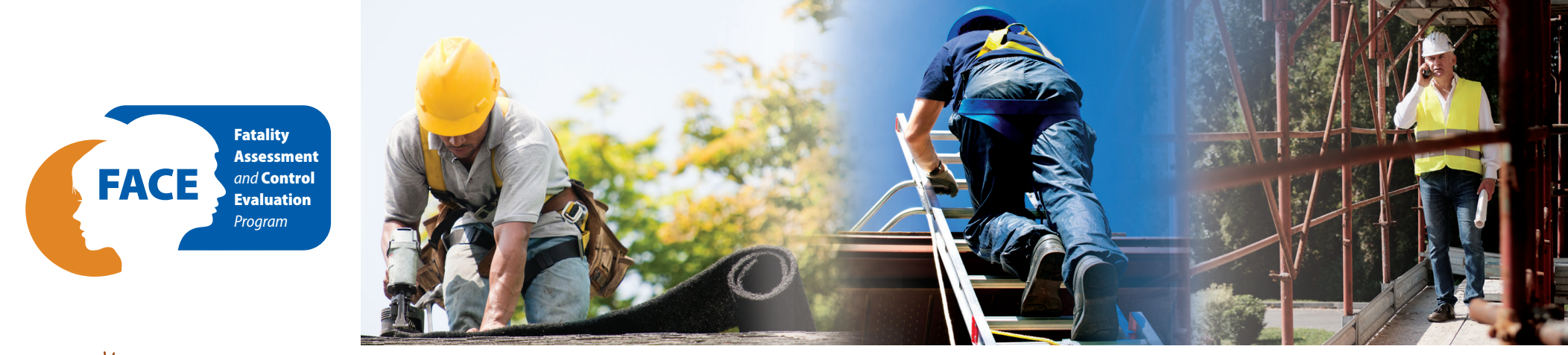

洸: Use these resources to prevent falls and keep construction workers safe on the job.

\section{Construction Falls Resources}

NIOSH Construction Program

https://www.cdc.gov/niosh/programs/construction/

This website provides program goals and resources.

\section{NIOSH FACE Program}

https://www.cdc.gov/niosh/face/

This website provides NIOSH FACE and State FACE reports.

\section{NIOSH Falls in the Workplace}

https://www.cdc.gov/niosh/topics/falls/

This website provides information about projects and resources available to prevent work-related falls.

\section{NIOSH FACE Program: A Five Year Look-Back}

https://www.youtube.com/watch?v=OONUcRmoaQQ

This video highlights the NIOSH FACE Program and the role the FACE states have in promoting the National Campaign to Prevent Falls in Construction.

\section{Stop Construction Falls Campaign}

\section{Websites and Materials}

\section{Campaign Websites}

https://stopconstructionfalls.com/

https://www.cdc.gov/niosh/construction/stopfalls.html

https://www.osha.gov/stopfalls/

Get information to prevent falls and participate in the

National Safety Stand-Down event.

\section{Fall Prevention Fact Sheet}

https://www.cdc.gov/niosh/docs/2012-142/pdfs/2012-142.pdf This fact sheet provides information to PLAN ahead to get the job done safely. PROVIDE the right equipment. TRAIN everyone to use the equipment safely.

\section{Acknowledgments: The NIOSH FACE Program thanks the KY FACE, MA FACE, and OR FACE programs for their} investigation reports that are highlighted in this fact sheet.

Mention of any company or product does not constitute endorsement by the National Institute for Occupational Safety and Health, Centers for Disease Control and Prevention. In addition, citations to websites external to NIOSH do not constitute NIOSH endorsement of the sponsoring organizations or their programs or products. Furthermore, NIOSH is not responsible for the content of these websites. All web addresses referenced in this document were accessible as of the publication date.

\section{Ladder Resources}

\section{NIOSH Ladder Safety App}

https://www.cdc.gov/niosh/topics/falls/mobileapp.html

Download and use the free NIOSH Ladder Safety app to prevent extension and step-ladder fall injuries and deaths.

\section{Ladder Safety: There's an App for That}

http://blogs.cdc.gov/niosh-science-blog/2013/08/27/laddersafety/

This NIOSH Science Blog shares information about development of the app and its use among workers.

\section{About the FACE Program}

The National Institute for Occupational Safety and Health's (NIOSH) Fatality Assessment and Control Evaluation (FACE) Program, along with its State FACE partners, study fatal workplace injuries and prepare reports with recommendations to prevent similar deaths.

This national research program aims to prevent job-related injuries and deaths by:

- Investigating select deaths

- Identifying hazards

- Developing workplace prevention recommendations

- Sharing recommendations with employers, safety professionals, and workers

See our Fatality Assessment and Control Evaluation (FACE) Program flyer for more information. 